\title{
School Counselor Use of Narrative Therapy to Support Students of Color Transitioning from an Alternative School Setting
}

\author{
Natoya Hill Haskins \\ The College of William and Mary
}

Lee E. Grimes

Valdosta State University

\author{
Leonissa Johnson \\ Clark Atlanta University
}

\author{
Autumn Joy Moore \\ Clarke County (GA) School District
}

\author{
Candice Norris-Brown \\ Indiana Wesleyan University
}

W ith increasing diversity over the last several decades, social constructionist approaches such as narrative therapy have been instrumental in addressing various populations' unique needs (Combs \& Freedman, 2012; Murdock, Duan, \& Nilsson, 2012; Semmler \& Williams, 2000). For instance, narrative therapy has been found to be beneficial when working with populations experiencing life changes ranging from school transitions (Lewis, 1990) to oppression and marginalization (Combs \& Freedman, 2012). More recently researchers have applied narrative concepts with children and adolescents to revise personal narratives about difficult school experiences (Eppler, Olsen, \& Hidano, 2009; Nafzinger \& DeKruyf, 2013; Thomas \& Gibbons, 2009).

The application of narrative therapy has substantial implications for school counselors and school personnel who provide support to students transitioning from alternative settings back into traditional school environments. School counselors and school personnel have used various frameworks to assist transitioning students (e.g., mentoring, student monitoring, case management, family outreach, schoolbased curricular reforms, the Check and Connect program) (Scheel, Madabhushi, \& Backhaus, 2009; Tyler \& Lofstrom, 2009). However, they have failed to consider how the student may view him or herself or how others may treat the student upon returning to a traditional school setting. These programs also fail to deal with the psychological stressors that students may face during the transition due to stigma and marginalization. In addition, there is limited information related to the efficacy of these current approaches, as many students who transition from an alternative setting will eventually return to that alternative setting or drop out (Knesting, 2008). A collaborative narrative approach would allow school counselors to use an empirically sound counseling framework to address the psychological stress associated with the transition as well as assist students in creating a new narrative through peer connections, parent involvement, and teacher support, which can enhance students' successes (Stewart, 2007).

Narrative therapy also allows students of color to transform hindering narratives into personal stories that empower, encourage productivity and counter oppression (Combs \& Freedman, 2012; Hartman, Little, \& Ungar, 2008; Murdock et al., 2012). In this regard, school counselors can use narrative therapy to help students of color identify their narratives of defeat and oppression, highlight alternative behaviors within their stories and reduce the limiting effects of previous actions (Biever, McKenzie, Wales-North, \& Gonzalez, 1995; Combs \& Freedman, 2012). This social justice 
orientation of narrative therapy suggests it is an ideal approach for students of color transitioning from alternative programs and experiencing marginalization (Combs \& Freedman, 2012).

The purpose of this article is to describe how school counselors can use narrative therapy to help students of color successfully transition from alternative school placements back into the local school or traditional school setting. Further, the article will address challenges current school counselors experience when supporting transitioning students. In the next sections, the authors will provide an overview of alternative school and transitions background literature, discuss the foundations of narrative therapy, and use a case illustration to examine narrative therapy as a collaborative application approach for a student of color transitioning from an alternative school setting.

\section{ALTERNATIVE SCHOOLS}

Students started attending schools in alternative settings during the 1950s when traditional school settings did not meet the educational needs of particular students (Caroleo, 2014; Turton, Umbreit, \& Mathur, 2011). Alternative schools are school district or state governed entities typically designed to support underperforming students and those with learning disabilities and emotional or behavioral issues, as well as those who exhibit a high risk of dropping out of school or need individualized instruction (Porowski, O'Conner, \& Luo, 2014; Witty, 2009). In contrast, traditional school settings are school-district governed public institutions, where the student's grade level and where he or she resides in the school district dictate placement (Turton et al., 2011). Data from the National Center for Education Statistics indicate that $64 \%$ of U.S. school districts have at least one alternative school or program for students who are unable to remain in traditional school settings (Carver, Lewis, \& Tice, 2010). In the U.S., alternative programs serve 645,500 students in grades 9 through 12 (Carver et al.,
2010), with school districts primarily comprised of students of color equaling more than a third of the total number of students in alternative settings (Carver et al., 2010).

While alternative schools can decrease student dropout rates, encourage diverse approaches to teaching and learning, and prepare students for college (Hoye \& Sturgis, 2005; Lagana-Riordan et al., 2011), many students will transition back to a traditional educational environment. In this regard, most (63\%) U.S. school districts have policies that allow students to return and re-enroll in a traditional or zoned school based on students' demonstrated improved behavior, motivation to return, evidence of improved grades, and the approval of both alternative school and zoned school staff (Carver et al., 2010). As a result, $68 \%$ of students placed in alternative settings return to a traditional school setting (Carver et al., 2010).

Transition support services are imperative as many students in alternative programs experience significant social justice challenges, such as discrimination and stereotyping (McNulty \& Roseboro, 2009; Phillips, 2013), social difficulties (e.g., developing friendships, engaging in extracurricular activities, and adjusting to the social climate), as well as academic and personal adjustment concerns (Eggleston \& Lanaan, 2001; Neild, StonerEby, \& Furstenberg, 2008) in their alternative school. Additionally, students who experience marginalization due to race or ethnicity are typically less successful than their peers in alternative settings (McNulty \& Roseboro, 2009; Phillips, 2013).

\section{TRANSITIONS}

Students moving from alternative settings back into schools experience hardships related to this transition process. West, Sweeting, and Young (2010) noted that students impacted by younger age, lower socio-economic status, lower ability levels, lower self-image issues, 
and more problematic behaviors (e.g., arduous peer relationships, challenging transitions to the secondary school setting) are more susceptible to difficult transition periods. In this regard, students transitioning from alternative settings demonstrate many of these behaviors or characteristics (Benner \& Graham, 2009). Specifically, transitioning to a traditional high school from an alternative program for many adolescents is difficult, due in part to the move from a personalized smaller educational environment, typical of the alternative setting, to a more complex school setting (Berger \& Malaney, 2003; Eggleston \& Lanaan, 2001). Additionally, transitioning students experience higher levels of stress and anxiety due to the lack of continuity and new environmental demands (Benner \& Graham, 2009; Dacey \& Travers, 1991). School transition can also be more stressful for African American and Latino students when they reenter traditional schools where fewer peer members of the same ethnicity are present (Benner \& Graham, 2009). The new traditional settings often lead to feelings isolation, anger, and marginalization for students of color (Lagana-Riordan et al., 2011). Implementing a collaborative narrative therapy approach can afford school counselors the opportunity to address the needs of students of color who experience difficulties with the transition process.

\section{NARRATIVE THERAPY}

Counselors using narrative therapy contend that reality is subjective and view problems as socially and culturally constructed (Combs \& Freedman, 2012; Semmler \& Williams, 2000). In addition, the hallmark of narrative therapy is personal storytelling that allows individuals to revise oppressive narratives from the past to new empowering narratives. Consequently, counselors using narrative therapy work collaboratively with students to empower them to explore their life through the stories they tell. The storytelling process creates an opportunity for counselors to help students re-tell or reauthor their stories so that versions marked by problems can become new and reflect the students' strengths used to overcome the problems (Murdock et al., 2012).

The process of identifying problems as separate from people is narrative therapy's most notable theoretical construct (Combs \& Freedman, 2012). With its deconstruction of dominant cultural messages and a focus on personal power inherent in the creation of the student's new story, narrative therapy is a social justice practice (Combs \& Freedman, 2012). Consequently, narrative therapy helps students confront issues of inequity while also supporting students as they seek more equitable and empowering personal narratives. In this regard, counselors effectively use narrative therapy with diverse populations navigating various social justice and diversity issues (Gwozdziewycz \& MehlMadrona, 2013; Santos, Goncalves, Matos, \& Salvatore, 2009). Listed below is an overview of the narrative therapy process.

\section{NARRATIVE THERAPY PROCESS}

Be collaborative. The relationship between counselor and student is a significant narrative therapeutic aspect. The counselor must adopt a collaborative position that allows the student to be the expert in his or her own story (White, 1994). The counselor displays collaboration by favoring listening over questioning and demonstrating openness and acceptance of the student's intentions and values.

Externalize the problem. One primary assumption of narrative therapy is that the problem is the issue, not the person. Consequently, the counselor helps the student see him or herself as separate and distinct from the problem by using questions that emphasize how the problem has influenced life and relational experiences (e.g., Are you happy with what anger is doing to your relationships? How did transitioning come to oppress you?) 
(White, 1995). As a result, of this dialogue, the student can create a locus of control and internal agency regarding his or her life, thus presenting the opportunity to interrupt the current dominant problem-saturated story.

In the externalization process, the counselor and student examine the problem's influence on the student (White \& Epston, 1990). The externalization process helps the student identify how his/her family supports the problem. Through this process, the student can see him or herself as an author of the story, not a mere bystander or coauthor (Madigan, 2004). As counseling continues, the student may see instances when the oppressive power's influence was not as great and identify unique outcomes.

Identify exceptions and unique outcomes. In order to develop a sense of internal agency and control, students must identify the times they felt empowered. At this stage, the counselor encourages the student to identify actions, motivations, and beliefs that were present during times of empowerment, which contradict the current personal life narrative and provide a different and unique outcome (e.g., Can you discuss a time when this problem did not oppress you?) (White, 1995). The student develops new meanings about himself/herself and subsequently creates a new narrative. It is critical that the counselor helps the student understand how a new narrative could change his/her personal and relational interactions.

Thicken story using consciousness questions. The "thickening" process allows the student to elucidate his/her story as viewed by both the student and others. This thickening enables the counselor to understand the student's value and belief systems, intentions, expectations, and motivations (White, 1994). The counselor asks the student to explain what meaning he/she gives to the identified event. The counselor can use information obtained from the thickening process to help the student examine how the meaning given to these events affected his/her past relationships (White \& Epston, 1990).

Link past to develop an alternative narrative. By linking the stories from the past to a new alternative-preferred narrative, the counselor illuminates the overlooked personal narrative, hidden by the dominant discourse. The ignored aspects of the personal narrative serve as a point of origination for creating and/ or enhancing a new personal narrative (Hall, McLean, \& White, 1994). As the student moves forward from the past and toward the person he or she wants to be, the counselor will examine this preferred new narrative with the student.

Invite witnesses to experience the new narrative. The student is more likely to continue to live this new preferred narrative when witnesses in the community can see and validate the new narrative (White, 1995). Individuals in the student's community can guard against regression and coach the student toward realizing the new narrative. The community members can also support the student as he/she faces challenges created by the new narrative.

Document gains. Using letters to solidify gains has a significant impact on the student and is one key narrative therapy technique. Students can write letters to reinforce the learning from therapy. In addition, in the letters, students may also describe the external nature of a specific problem and the influence on the student the problem presented. Finally, letters allow students to identify difficulties and struggles caused by the problem (McKenzie \& Monk, 1997).

\section{NARRATIVE THERAPY IN SCHOOLS}

School counselors can use a narrative approach effectively during individual and group counseling or classroom guidance interventions regarding academic achievement, mental health concerns, and personal/social skills development (Nafziger \& DeKruyf, 2013). Time constraints affect the work of school counselors, making 
the narrative approach especially effective because a school counselor and a student can collaboratively work to re-author the student's story in as few as three sessions (Thomas \& Gibbons, 2009). Notably, narrative counseling techniques may include the use of puppets to help understand the process and externalize problems (Butler, Guterman, \& Rudes, 2009), suggesting the approach can be very effective with elementary school children (Eppler et al., 2009) while also offering a potentially successful adolescent counseling approach (Biever et al., 1995; Larsen \& Larsen, 2004; Thomas \& Gibbons, 2009). For example, structured approaches based on narrative therapy have been effective with adolescents through programs such as the Structured-Relationship Model for Fostering Resiliency (Lewis, 1992), the Making Life Choices Program (Ferrer-Wreder et al., 2002), and the Phoenix Youth Program (Hartman et al., 2008).

\section{CASE ILLUSTRATION}

The sample case is of a student who had trouble because of his placement in an alternative setting and his subsequent transition back into a traditional school setting:

Derrick, an African American 14 year old, recently started his ninth grade year at a traditional high school after he attended an alternative school setting due to behavioral difficulties with his classmates, teachers, and administrators in middle school. The traditional school demographics consist of 70\% White, 15\% African American, 10\% Latino/a, and 5\% other, with $30 \%$ of the students receiving free and reduced lunch. Before leaving the alternative school, Derrick had average grades and limited difficulties with teachers and administration. Since returning to a traditional school, he has experienced isolation by classmates and reports feeling "overlooked" by teachers. Derrick's mother also reports that she feels as if the "school has given up on him." Derrick has also experienced several instances of racism and discrimination since returning. As a result, Derrick is more withdrawn, which is affecting his grades, and the administration fears he may be retained in the ninth grade. The school requested that he receive psychological testing, which indicated that he is within normal range regarding $I Q$ and emotional capacities. However, this experience, along with the relational challenges, has left Derrick feeling marginalized and oppressed.

Derrick has been absent twice during the last week and when asked why he skipped school he stated that "it doesn't matter if I come to school or not." Derrick's father is not a consistent fixture in Derrick's life; however, Derrick's mother has tried to fill the gap by enrolling Derrick in a big brother program. Nevertheless, Derrick's mother works two jobs to take care of him and his two sisters. Derrick's mother feels like she is at her "wit's end" and does not know what else to do to address Derrick's behavior.

\section{NARRATIVE THERAPY STRATEGIES WITH THE STUDENT}

Session one (story and naming). A school counselor employing narrative therapy would focus on hearing Derrick's story during the first session. Counselors engaging in narrative therapy listen more than question using caring, non-judgmental active listening skills (Ivey, D’Andrea, Ivey, \& Simek-Morgan, 2007; Madigan, 2011). Listening in this way would allow Derrick to be the story's "expert" (Madigan, 2011). The school counselor would attentively attend to Derrick's described experiences before, during, and after the alternative school experience. The counselor would focus on the themes permeating Derrick's "problem-saturated" story. The school counselor would also note any narrative-implied strengths or resources.

The school counselor would then help Derrick define or name the problem. The school counselor could ask Derrick an openended question such as "What do you think the 
problem is?" (Lambie \& Milsom, 2010) and allow Derrick to identify the difficulty influencing his life. Together Derrick and the school counselor would name the problem, thus beginning the process of separating Derrick from the problem and identifying the problem as connected to "Unhelpful Habits" (Madigan, 2011).

Session two (externalizing the problem). During Derrick's second narrative therapy session, the school counselor would help Derrick externalize the problem to allow him to realize a distinct separation between the "Unhelpful Habits" and himself. One therapeutic step in visualizing the "problem" from the "person" could include creating a symbol representing the "Unhelpful Habits." Derrick could, using any medium at the school counselor's disposal, create a picture or object, and Derrick could add elements to the symbol throughout the session or at the conclusion as a summary of the session.

A key strategy in externalizing the problem would be questioning (Madigan, 2011; White, 1995). The school counselor would ask questions that allow Derrick to consider how "Unhelpful Habits" affect his life, such as "Derrick, how long have the Unhelpful Habits been around you?", "Can you describe ways you were persuaded into using these Unhelpful Habits?", "What did you gain because of these Unhelpful Habits?", "How do the Unhelpful Habits influence your relationships with your teachers...other students?", or "What pain have the Unhelpful Habits caused?" These questions would help Derrick examine the problem as something completely separate from himself.

Session three (exceptions and unique outcomes and thickening). Once Derrick sees the problem as separate from himself, the school counselor would focus on past behaviors that challenge Derrick's "Unhelpful Habits" narrative. During session three, the school counselor would ask Derrick questions such as "Can you describe a time when you overcame the Unhelpful Habits?" and "What helped you take this step?" The school counselor would further process Derrick's unique outcomes by asking questions that allow him to "thicken" or more fully detail the occurrence. The school counselor would ask questions such as "Who or what helped you take this step?" or "When did you realize your step resulted in a different experience?" (White, 1994). The school counselor would note the "Helpful Habits" Derrick used to bring about the unique outcome to challenge the "Unhelpful Habits" narrative. The school counselor might ask, "I wonder what Helpful Habits you used to come into the office today?" and "What aided you in using those Helpful Habits?"

Throughout the counselor-student dialogue, the school counselor would write down the "Helpful Habits" (Madigan, 2011). To help Derrick remain aware of his "Helpful Habits" narrative, the school counselor may instruct Derrick to record each instance he used the habits prior to the next session.

Session four (unique accounts and reauthoring). At the start of session four, the school counselor would ask Derrick to share his "Helpful Habits" list and identify instances during the previous week when his behavior matched his "Helpful Habits" narrative. Derrick could, for example, cite examples such as saying hello to another student, speaking politely to his teacher, or describe positive classroom behaviors. The school counselor would draw attention to the discrepancies between Derrick's "Helpful" and "Unhelpful" stories; focus specifically on Derrick's successes by asking questions such as "How were you able to get through the school day without Unhelpful Habits disturbing you?" and "How did you keep the Unhelpful Habits from pushing you around?" (Madigan, 2011; White \& Epston, 1990).

While listening to Derrick's story of "Helpful Habits" the school counselor would emphasize the Narrative Therapy re-authoring process. The school counselor would ask "What does this tell you about yourself?" or "Do you see these 
Helpful Habits as good or bad for you... How?" and "Can you see yourself continuing these habits over the next few days/weeks/months?" (Madigan, 2011; Madigan \& Epston, 1995).

As Derrick provides hopeful responses, the school counselor would pose unique circulation questions to develop a new story and help Derrick consider other individuals who can support the new narrative. The school counselor should use questions such as "Who would be least surprised that you are using these Helpful Habits?" or "Who may have first noticed you using your Helpful Habits?" These questions would highlight the positive individuals already supporting Derrick (Madigan, 2011).

The final portion of the fourth session would require Derrick to both create a lifeline for the upcoming month and create a plan for sharing his "new" story. The lifeline would help Derrick visualize the steps needed during the upcoming weeks to continue fulfilling his new narrative. Once the lifeline is complete, the school counselor would ask Derrick if he would share his lifeline with significant individuals such as his mother or others mentioned in response to the unique circulation questions. The school counselor would invite those individuals to the final session as witnesses to Derrick's new story.

Session five (witness a new story). The final session would provide Derrick with an opportunity to share his new story with witnesses. Derrick would specifically identify individuals including his mother, supportive teachers, or community members who know him well. Witnesses could also include clergy members or other friends or family identified by Derrick. Witnesses can share their positive feelings about Derrick and offer him encouragement. Before concluding the session, the group would discuss strategies to assist Derrick as he continues living his new story over the next month and beyond. The school counselor may begin this discussion with a question such as "Derrick, what support will you need from us as you use Helpful Habits?"
(Madigan, 2011). This question would likely generate ideas from Derrick and his witnesses.

\section{COLLABORATING WITH OTHER STAKEHOLDERS USING NARRATIVE THERAPY}

Familial and school factors can influence students' transition from alternative settings (Frey, Ruchkin, Martin, \& Schwab-Stone, 2009). Adolescents who were connected to the school (e.g., participated in clubs, organizations, sports), received teacher support, parental control (e.g., parents maintained discipline and provided boundaries), and limited exposure to violence had more positive outcomes when transitioning (Frey et al., 2009). Consequently, including parents and teachers in the narrative process would be essential for Derrick to revise his disempowering narrative.

Strategies with parents. One way to continue supporting Derrick during and after the transitional period would be to use narrative therapy to assist his parent. The school counselor would listen to his mother's account of the events that led Derrick to attend alternative school and raise questions about possible oppression and disempowerment. The school counselor may explore multiple facets of identity such as race, socioeconomic status, language acquisition, or health conditions. Madigan (2011) recommended posing questions such as "Do you think race had something to do with how Derrick was treated?" or "How does it feel to have your son exposed to an education system where he might get treated differently because of the color of his skin?" The school counselor should demonstrate empathy by ensuring that the counselor believes the mother's story, understands that she went through a difficult experience, and has support moving forward.

The school counselor also can ask Derrick's mother to identify school-based actions that would help both Derrick and her feel the school community supports them. In addition, the school counselor can solicit feedback from 
Derrick's mother regarding community members who know Derrick's reputation as a kind, hardworking student. The school counselor would further aid Derrick's family by writing letters to school teachers and administrators detailing the oppression issues revealed through Derrick's and his mother's stories. The school counselor could personally encourage school leaders to change any lingering negative perceptions they may have of Derrick (Madigan, 2011; White \& Epston, 1990).

In addition, the school counselor could ask community members identified by Derrick and his mother to write letters of support to Derrick. Letters from community members would be encouraging and detail thoughts and feelings about the contributions Derrick made to the community, ways Derrick could continue improving his behavior, and ways they envision their relationship with Derrick in the future (Madigan, 2011; Madigan \& Epston, 1995).

Strategies with teachers. One way to assist Derrick during the transitional period would be with his teachers. The school counselor should use questions such as "Of all the teachers at school, who would be least surprised that you are using Helpful Habits?" The questions would highlight any teachers within Derrick's support network (Madigan, 2011; White \& Epston, 1990). If permitted, the school counselor could invite these teachers to witness Derrick's new story. The school counselor would educate these teachers about the narrative therapy and encourage them to consider how Derrick has positively influenced the school community. Once Derrick has shared his new story, teachers can suggest ways to aid Derrick at school.

As members of the school community, teachers can assist with sharing Derrick's new narrative to different groups in the school system. The school counselor would ask teachers how they would honor Derrick's new story. Teachers can integrate Derrick's new narrative into their classrooms by recognizing Derrick for "Helpful Habits" witnessed in school.
Teachers can write Derrick and his mother letters of support describing the positive ways Derrick contributes to the school community. By using their voices, teachers can circulate Derrick's "Helpful Habits" narrative to students, teachers and administrators.

\section{IMPLICATIONS FOR PRACTICE AND RESEARCH} Narrative therapy calls upon practitioners to examine current counseling practice and encourages them to consider using postmodern approaches that embrace inclusivity to address overlooked concerns for students of color. Narrative therapy provides school counselors with a detailed guide for moving beyond traditional models of counseling practice in order to assist populations, like students transitioning from alternative to traditional school settings, which would benefit from creating and living a new narrative. The integration of stakeholders like parents and teachers can also provide this student population an opportunity to receive support from witnesses engaged in the students' environment. The additional stakeholders can likewise take part in an aspect of the counseling process, which may help them to understand students and the school counselor's role. Furthermore, professional school counselors, who are often limited on time, would benefit from applying counseling approaches that solicit the support of parents and teachers.

Currently, limited conceptual literature exists on the school counselor's role with students transitioning from alternative settings to traditional schools. Research to examine these processes would expand the current literature and potentially develop best practices. Researchers need to explore the implementation of narrative therapy with this population to determine which students would most benefit from this counseling approach. Moreover, research studies related to collaborative narrative approaches that involve counseling allies would be useful. Studies that compare the collaborative approaches' outcomes to 
traditional counselor/student counseling interactions would serve to better understand the gaps in traditional models of counseling. Scholars can also examine how to incorporate School-Family-Community-Partnerships as a framework for alternative school transitions (Bryan \& Henry, 2012). Researchers should also investigate how this collaborative narrative approach could be crossed-walked with the Recognized American School Counseling Association Model Program (RAMP) process to enhance school counselors' ability to apply these standards and guidelines and meet the needs of transitioning students. Finally, scholars can explore how this collaborative approach may influence school counselors' multicultural and social justice competence and their ability to apply the national Multicultural/Social Justice and Advocacy Competencies (Ratts et al., 2015).

\section{LIMITATIONS}

Although there are many benefits to using narrative therapy with students transitioning from alternative school placement back to a traditional school, there are limitations as well. First, for narrative therapy to be successful, students need to be self-reflective and willing to think of themselves in terms of their stories. Some students are naturally more reflective and articulate. If students resist, the process could end at session one. While narrative therapy can occur in as little as three sessions, following each of the steps outlined here would require more sessions. Coordinating the presence of witnesses from the community to hear the student's story could be complicated as could gathering letters written by community members. Finally, determining the effectiveness of the intervention could be a limitation as multiple factors contribute to the success or failure of students returning to the local school after alternative school placement. Despite its limitations, using narrative therapy with transitioning alternative school students holds great potential.

\section{CONCLUSION}

Students transitioning from alternative school settings and returning to their traditional school environment often have a difficult re-adjustment period. Without appropriate transition support, students may repeat the offending behavior that led to the alternative school placement. A school counselor using a narrative therapy approach can help students envision a new "story" and embrace a way of being while also combating the marginalization and oppression students may experience during transition. This approach also addresses the importance of parents' and teachers' roles in ensuring that students are successful in their transition. Finally, a narrative therapy approach also can help school counselors advocate for change since it assists students in finding their new stories, stories that may inspire other students experiencing issues with the transition process.

\section{REFERENCES}

Benner, A. D., \& Graham, S. (2009). The transition to high school as a developmental process among multiethnic urban youth. Child Development, 80, 356-376. doi:10.1111/ j.1467-8624.2009.01265.x

Berger, J. B., \& Malaney, G. D. (2003). Assessing the transition of transfer students from community colleges to a university. Journal of Student Affairs Research and Practice, 40(4), 533-723. doi:10.2202/1949-6605.1277

Biever, J. L., McKenzie, K., Wales-North, M., \& González, R. C. (1995). Stories and solutions in psychotherapy with adolescents. Adolescence, 30(118), 491499.

Bryan, J., \& Henry, L. (2012). A model for building school-family-community partnerships: Principles and process. Journal of Counseling \& Development, 90, 408-420. doi:10.1002/ j.1556-6676.2012.00052.x

Butler, S., Guterman, J. T., \& Rudes, J. (2009). Using puppets with children in narrative therapy to externalize the 
problem. Journal of Mental Health Counseling, 31, 225-233. doi:10.17744/ mehc.31.3.f255m86472577522

Caroleo, M. (2014). An examination of the risks and benefits of alternative education. Relational Child \& Youth Care Practice, 27, 35-46.

Carver, P. R., Lewis, L., \& Tice, P. (2010). Alternative schools and programs for public school students at risk of educational failure: 2007-08. U.S. Department of Education, National Center for Education Statistics. Washington, DC: Government Printing Office. Retrieved from http://nces.ed.gov/ pubs2010/2010026.pdf

Combs, G., \& Freedman, J. (2012). Narrative, poststructuralism, and social justice: Current practices in narrative therapy. The Counseling Psychologist, 40, 1033-1060. doi:10.1177/0011000012460662

Dacey, J., \& Travers, J. (1991). Human development across the lifespan. Dubuque, IA: Brown Publishers.

Eggleston, L. E., \& Laanan, F. S. (2001). Making the transition to the senior institution. New Directions for Community Colleges, 2001(114), 87-97. doi:10.1002/ cc. 23

Eppler, C., Olsen, J. A., \& Hidano, L. (2009). Using stories in elementary school counseling: Brief, narrative techniques. Professional School Counseling, 12, 387-391.

Ferrer-Wreder, L., Lorente, C. C., Kurtines, W., Briones, E., Bussell, J., Berman, S., \& Arrufat, O. (2002). Promoting identity development in marginalized youth. Journal of Adolescent Research, 17(2), 168-187.

Frey, A., Ruchkin, V., Martin, A., \& SchwabStone, M. (2009). Adolescents in transition: School and family characteristics in the development of violent behaviors entering high school. Child Psychiatry \& Human Development, 40, 1-13. doi:10.1007/ s10578-008-0105-x
Gwozdziewycz, N., \& Mehl-Madrona, L. (2013). Meta-analysis of the use of narrative exposure therapy for the effects of trauma among refugee populations. The Permanente Journal, 17(1), 70-76. http:// dx.doi.org/10.7812/TPP/12-058

Hall, R., McLean, C., \& White, C. (1994). Special edition on accountability. Dulwich Centre Newsletter, 2. Adelaide, Australia: Dulwich Centre Publications.

Hartman, L., Little, A., \& Ungar, M. (2008). Narrative-inspired youth care work within a community agency. Journal of Systemic Therapies, 27(1), 44-58. doi:10.1521/ jsyt.2008.27.1.44

Hoye, J. D., \& Sturgis, C. (2005). The alternative pathways project: A framework for dropout reduction and recovery. Retrieved from http://youthforachange.org/CRN-researchand-strategies.html

Ivey, A., D’Andrea, M., Ivey, M., \& Simek-Morgan, L. (2007). Counseling and psychotherapy: A multicultural perspective (6th ed.). Boston, MA: Allyn \& Bacon.

Knesting, K. (2008). Students at risk for school dropout: Supporting their persistence. Preventing School Failure, 52(4), 3-10. http://dx.doi.org/10.3200/PSFL.52.4.3-10

Lagana-Riordan, C., Aguilar, J. P., Franklin, C., Streeter, C. L., Kim, J.S., Tripodi, S. J., \& Hopson, L. M. (2011). At risk students' perceptions of traditional schools and a solution-focused public alternative school. Preventing School Failure, 55, 105-114. http://dx.doi. org/10.1080/10459880903472843

Lambie, G. W., \& Milsom, A. (2010). A narrative approach to supporting students diagnosed with learning disabilities. Journal of Counseling \& Development, 88, 196-203. doi:10.1002/j.1556-6678.2010.tb00009.x

Larsen, D. J., \& Larsen, J. E. (2004). "I am a puzzle": Adolescence as reflected in selfmetaphors. Canadian Journal of Counselling, 38, 246-259. 
Lewis, J. R. (1992). Psychometric evaluation of the Post-Study System Usability Questionnaire: The PSSUQ. Proceedings of the Human Factors and Ergonomics Society Annual Meeting, 36, 1259-1260. Retrieved from http://journals.sagepub.com/doi/ pdf/10.1177/154193129203601617

Lewis, J., Arnold, M. S., House, R., \& Toporek, R. (2003). Advocacy competencies. Retrieved from https://www.counseling. org/Resources/Competencies/Advocacy_ Competencies.pdf

Madigan, S. (2004). Child therapy with the experts. Alexandria, VA: Alexander Street Press.

Madigan, S. (2011). Narrative therapy: Theory and practice. Chicago, IL: APA Publications.

Madigan, S., \& Epston, D. (1995). From "spy-chiatric gaze" to communities of concern: From professional monologue to dialogue. In S. Friedman (Ed.), The reflecting team in action: Collaborative practice in family therapy (pp. 257-276). New York, NY: Guilford Press.

McKenzie, W., \& Monk, G. (1997). Learning and teaching narrative ideas. In G. Monk, J. Winslade, K. Crocket, \& D. Epston (Eds.), Narrative therapy in practice: The archaeology of hope (pp. 82-117). San Francisco, CA: Jossey-Bass.

McNulty, C. P., \& Roseboro, D. L. (2009). “I'm not really that bad": Alternative school students, stigma, and identity politics. Equity \& Excellence in Education, 42, 412-427. http:// dx.doi.org/10.1080/10665680903266520

Murdock, N. L., Duan, C., \& Nilsson, J. E. (2012). Emerging approaches to counseling intervention: Theory, research, practice, and training. The Counseling Psychologist, 40, 966-975. doi:10.1177/0011000012460663

Nafziger, J., \& DeKruyf, L. (2013). Narrative counseling for professional school counselors. Professional School Counseling, 16, 290-302.
Neild, R. C., Stoner-Eby, S., \& Furstenberg, F. (2008). Connecting entrance and departure: The transition to ninth grade and high school dropout. Education and Urban Society, 40, 543-569. doi:10.1177/0013124508316438

Phillips, R. S. (2013). Toward authentic student-centered practices: Voices of alternative school students. Education and Urban Society, 45, 668-698. doi:10.1177/0013124511424107

Porowski, A., O’Conner, R., \& Luo, J. L. (2014). How do states define alternative education? (REL 2014-038). Washington, DC: U.S. Department of Education. Retrieved from http://ies.ed.gov/ncee/edlabs.

Ratts, M. J., Singh, A. A., Nassar-McMillan, S., Butler, S. K., McCullough, J. R., \& HipolitoDelgado, C. (2015). Multicultural and social justice counseling competencies. Alexandria, VA: AMCD.

Santos, A., Gonçalves, M., Matos, M., \& Salvatore, S. (2009). Innovative moments and change pathways: A good outcome case of narrative therapy. Psychology and Psychotherapy: Theory, Research and Practice, 82, 449-446. doi:10.1348/147608309X462442

Scheel, M. J., Madabhushi, S., \& Backhaus, A. (2009). The academic motivation of at-risk students in a counseling prevention program. The Counseling Psychologist, 37, 1147-1178. doi: 10.1177/0011000009338495

Semmler, P. L., \& Williams, C. B. (2000). Narrative therapy: A storied context for multicultural counseling. Journal of Multicultural Counseling and Development, 28, 51-62. doi:10.1002/j.2161-1912.2000.tb00227.x

Stewart, E. B. (2007). Individual and school structural effects on African American high school students' academic achievement. The High School Journal, 91(2), 16-34. http://dx.doi.org/10.1353/hsj.2008.0002

Thomas, D. A., \& Gibbons, M. M. (2009). Narrative theory: A career counseling approach for adolescents of divorce. Professional School Counseling, 12, 223-229. 
Turton, A. M., Umbreit, J., \& Mathur, S. R. (2011). Systematic function-based intervention for adolescents with emotional and behavioral disorders in an alternative setting: Broadening the context. Behavioral Disorders, 36, 117-128.

Tyler, J. H., \& Lofstrom, M. (2009). Finishing high school: Alternative pathways and dropout recovery. The Future of Children, 19(1), 77-103.

West, P., Sweeting, H., \& Young, R. (2010). Transition matters: Pupils' experiences of the primary-secondary school transition in the west of Scotland and consequences for well-being and attainment. Research Papers in Education, 25, 21-50. http:// dx.doi.org/10.1080/02671520802308677

White, M. (1993). Deconstruction and therapy. In S. Gilligan \& R. Price (Eds.), Therapeutic conversation (pp. 22-61). New York, NY: Norton.

White, M. (1995). Re-authoring lives: Interviews and essays. Adelaide, Australia: Dulwich Centre Publications.

White, M., \& Epston, D. (1990). Narrative means to therapeutic ends. New York, NY: WW Norton \& Company.

Witty, J. V. (2009). Exemplary practices in alternative education: Indicators of quality programming. Manassas, VA: National Alternative Education Association.

Natoya Hill Haskins is an assistant professor at the College of William and Mary. Her expertise encompasses school counseling and family issues as well as effective cross-cultural training experiences for students of color. Her research interests include students and faculty of color educational and professional supports, advocacy instrumentation, and the application of culturally responsive theoretical frameworks in training and counseling settings.
Leonissa Johnson is an assistant professor at Clark Atlanta University in Atlanta, Georgia. Her research interests include addressing the counseling needs of English Learners in schools, school counselor self-efficacy, and counselor advocacy.

Lee E. Grimes is an assistant professor of Counselor Education at Valdosta State University. Her research interests include rural school counseling, social justice in school counseling, and best practices for school counselors in career counseling. Her expertise includes professional school counseling experience at the elementary, middle, and high school levels.

Autumn Joy Moore is a full-time middle school counselor in Athens, Georgia.

Candice Norris-Brown, LPC, NCC, is faculty member at Indiana Wesleyan University. She enjoys advocating for children and spending time with family and friends. Her current interests include advocating for students with disabilities and marginalized groups that experience systemic barriers, group work, professional identity of professional school counselors, and clinical supervision.

$* * * * * * * * * * * * * * * * * * * * * * * * * * * * * * * * * * * * * *$ 